\title{
Habitus e Corpo Social: reflexões sobre o corpo na teoria sociológica de Pierre Bourdieu
}

\author{
Cristina Carta Cardoso de Medeiros ${ }^{*}$
}

\begin{abstract}
Resumo: Este texto propõe discutir como as reflexões sobre o corpo estão presentes na teoria sociológica de Pierre Bourdieu, articulando o conceito de habitus e a construção do corpo social. Tal articulação pode ser verificada em várias obras de Bourdieu em que analisa as disposições incorporadas, o esquema corporal, os movimentos, as técnicas e os usos do corpo. Também foi possível verificar que Bourdieu reflete sobre o tema articulando-o em três eixos, a saber, o corpo como lugar do senso prático, o corpo como manifestação do habitus e o corpo como investimento de poder e dominação. Este entendimento auxilia na utilização do quadro teórico de análise desenvolvido por esse sociólogo para investigações sobre os processos de socialização, tornando-se uma importante ferramenta conceitual.

Palavras-chave: Corpo Humano. Sociologia. Pierre Bourdieu. Valores sociais.
\end{abstract}

\section{INTRODUÇÃO: UMA PERCEPÇÃO SOCIAL DO CORPO}

Em vários livros e artigos de Pierre Bourdieu, em épocas variadas de sua abrangente produção científica, pode-se observar o destaque das discussões sobre o corpo em sua obra, importando para o autor analisar as disposições incorporadas, verificar o esquema corporal, os movimentos, as técnicas e os usos do corpo como princípios ordenáveis, capazes de orientar as práticas de maneira inconsciente e sistemática.

É possível estabelecer algumas hipóteses sobre a germinação das noções que fariam com que esse sociólogo francês considerasse a centralidade do corpo em suas reflexões e que o teriam levado a perceber que as disposições incorporadas, transformadas em posturas

* Mestre e Doutora em Educação pela UFPR. Professora Adjunto do Departamento de Educação Física da UFPR. Professora colaboradora no PPGEF/UFPR. Pesquisadora do CEPELS (Centro de Pesquisas em Esporte, Lazer e Sociedade. Áreas de estudo: Dança, Sociologia da Educação, Sociologia do Esporte, Teoria Sociológica de Pierre Bourdieu. E-mail: crisccm@ufpr.br 
corporais, é que permitem compreender de que maneira o homem se socializa.

Para Hong (1999), a posição de destaque do corpo na formulação bourdieusiana do habitus se deu a partir da influência de Maurice Merleau-Ponty ${ }^{1}$ e justifica seu posicionamento alegando que a importância do filósofo nas teorizações de Bourdieu é de dupla natureza: primeiramente porque tornou possível a crítica que o sociólogo fez ao subjetivismo sartriano $^{2}$ e, em segundo lugar, pela possibilidade de destacar a "temática merleau-pontiana da percepção" , inscrita em uma genealogia da Filosofia do corpo, na qual também se pode ligar a noção bourdieusiana do habitus.

Corroborando com tais afirmações, Sapiro (2004) também comenta que a leitura de textos de Merleau-Ponty teve grande influência em Bourdieu, tanto como um modelo intelectual alternativo para o distanciamento do existencialismo de Sartre, mas porque tais leituras e as reflexões sobre o corpo delas advinda, foram determinantes na gênese da teoria do habitus.

Wacquant (1992, p.27) aponta, igualmente, que algumas idéias de Merleau-Ponty inspiraram Bourdieu teoricamente como, em particular, a da "corporeidade intrínseca do contato pré-objetivo entre sujeito e objeto", de modo a restituir o corpo como fonte de uma intencionalidade prática, ou seja, tratar o corpo socializado não como um objeto, mas como o depósito de uma capacidade gerativa e criativa. A relação entre agente social e o mundo não seria a relação entre um indivíduo e um objeto, mas a relação de cumplicidade ontológica entre o habitus e o mundo que o determina. Esta explicação é dada pelo próprio Bourdieu (2002a) quando escreve sobre a gênese dos conceitos de habitus e de campo.

Mas o que permite uma aproximação mais efetiva entre

\footnotetext{
${ }^{1}$ Filósofo fenomenologista francês que fundamentou sua teoria no comportamento corporal e na percepção.

2 Segundo Wacquant (2006, p.16), "desde os seus primeiros trabalhos, Bourdieu opôs-se à 'Antropologia imaginária' de Sartre, que secularizou a visão cartesiana de uma consciência auto-constituída e criadora do mundo, recorrendo à concepção de Merleau-Ponty de um corpo vivo como produto-produtor sintético da realidade social e receptáculo ativo de forças passadas". ${ }^{3}$ HONG, 1999, p.70

Vovimento, Porto Alegre, v. 17, n. 01, p. 281-300, janeiro/março de 2011.
} 
Bourdieu e Merleau-Ponty, bem como buscar compreender a centralidade do corpo no conceito de habitus e a relevância que Bourdieu atribui ao corpo social em suas pesquisas, é a questão do "esquema corporal". Em sua abordagem sociológica utiliza o "esquema corporal" para interpretar as posturas corporais, ou mesmo os usos do corpo na vida cotidiana. Esta noção é fundamental para o entendimento das observações posteriores que o sociólogo faz sobre a incorporação do habitus e sobre o esquema corporal como depositário de toda uma visão do mundo social em que se refletem os distintos usos do corpo nos diferentes grupos sociais ${ }^{4}$.

Segundo Hanks (2008, p.37), pode-se afirmar que existe, em uma linha de reflexão presente na elaboração do habitus, os conceitos fenomenológicos de habilidade e de esquema corporal. Defendendo seu ponto de vista, este autor comenta que,

\begin{abstract}
O deslocamento decisivo aqui é o da noção de disposição para a noção de corporificação (embodiment). O esquema corporal de Merleau-Ponty não é nem uma representação do corpo, nem uma mera avaliação de sua dimensão física. Ao contrário, é a prise de conscience (tomada de consciência), o entendimento momentâneo que o sujeito tem de ser um corpo. Isso inclui, entendidas em conjunto, tanto a real disposição da postura do corpo, quanto o horizonte de possibilidades para outras disposições possíveis da postura corporal, mas não realizadas. Neste ponto, Bourdieu, a exemplo dos fenomenologistas, está interessado na familiaridade e na imediatez da experiência corporal, sendo ambas herdadas pelo habitus.
\end{abstract}

Buscando outros pontos de aproximação entre Bourdieu e Merleau-Ponty, Hong (1999) afirma que para Merleau-Ponty, o movimento do corpo não é um pensamento, mas um hábito adquirido em um determinado tempo. O hábito se apresenta, então, como essencialmente motor e perceptivo. O "esquema corporal", quer ele funcione como percepção ou como motricidade, só pode se constituir apropriando-se dos principais instrumentos culturais.

${ }^{4}$ Verificar em BOURDIEU, 2002b.

Movimento, Porto Alegre, v. 17, n. 01, p. 281-300, janeiro/março de 2011. 
Não é simplesmente um resumo de nossa experiência corporal, mas deve ser entendido como o hábito geral, como aquisição do mundo ao nível da percepção e dos atos, sendo então uma maneira de expressar que o corpo está no mundo. Hong (1999) ressalta que em sua obra Fenomenologia da Percepção, Merleau-Ponty descreve o corpo como um lugar de apropriação do sentido do mundo. Embora o fenomenólogo nunca tenha utilizado a expressão "corpo social”, a dimensão social está implicitamente colocada em seus textos sobre o esquema corporal.

Já na teoria de Bourdieu fica claro que a maneira de estar no mundo se deve a um processo de pertencimento social. Em outras palavras, o indivíduo é um coletivo encarnado, um social incorporado. A relação do corpo com o mundo é, implícita e explicitamente, ligada à imposição de uma representação legítima do corpo.

Outro aspecto em que se pode realizar uma aproximação teórica entre Bourdieu e Merleau-Ponty diz respeito à expressão corporal. $\mathrm{O}$ corpo expressivo, enquanto corpo que se comunica, que demonstra raiva, amor, aversão, aceitação, pudor, sexualidade, em uma comunicação sem palavras, somente pela gestualidade, é um corpo que apesar de expressivo, por isso particular de cada indivíduo, segue um "esquema corporal social"s. Ele só pode ser compreendido enquanto um corpo que se comunica, porque outros detêm o mesmo signo expressivo.

Esclarecendo a expressividade corporal, segundo as teorias de Merleau-Ponty, Hong (1999) ressalta que todo uso do corpo expressivo é uma atitude em relação ao mundo social. Por mais que esta expressão corporal tenha uma regulamentação, é sempre uma nova atitude, já que se executa a partir de um estilo, de uma configuração de caráter individual e própria de cada agente em relação a uma nova situação. Pensa-se, assim, na proposta da noção do habitus em Bourdieu que, enquanto prática geradora, mesmo sendo parte de um sistema de disposições regulares e reguladas, origina formas diferenciadas de expressar-se corporalmente, dentro das modulações configuradas por um grupo socialmente identificado.

${ }^{5}$ HONG, 1999, p. 81.

Movimento, Porto Alegre, v. 17, n. 01, p. 281-300, janeiro/março de 2011. 
Pode-se encontrar explicações complementares para os pressupostos acima citados com Champagne (2008) para quem o agente é dotado de um habitus que inscreveu em seu corpo o processo de socialização e de experiências passadas. Permite perceber que os comportamentos são ao mesmo tempo prováveis e ao mesmo tempo nunca totalmente previsíveis porque o corpo não é uma coisa inerte, uma espécie de receptáculo passivo que obedece mecanicamente aos decretos da consciência.

Compreende-se, então, a existência de uma multiplicidade de gestos corporais que variam nas diferentes civilizações. Por vezes um mesmo gesto pode ter significados distintos, ligando de maneira particular, determinadas pessoas, enquanto uma maneira de ser no mundo.

O corpo social é o corpo do indivíduo portador do habitus, como um sistema de disposições duradouras que geram e estruturam práticas reguladas que são incorporadas e inconscientes ${ }^{6}$, por isso regularmente reproduzidas.

O corpo passa a ser portador do habitus uma vez que as disposições incorporadas moldam o corpo a partir das condições materiais e culturais, até torná-lo um corpo social. Este é o processo de socialização, produzindo um ser individual forjado nas e pelas relações sociais, fazendo da própria individualização um produto da socialização. Por isso a noção de habitus articula o individual e o coletivo.

A noção de habitus engloba o corpo porque enquanto disposição passa a orientar as práticas corporais que traduzem uma maneira de ser no mundo. Para Bourdieu (2001, p.165), "é preciso um corpo para existir no mundo, para ser incluído no mundo, mas segundo um modo de inclusão irredutível à simples inclusão material e espacial". Estas disposições incorporadas pelo corpo passam a ser também duradouras, no sentido de serem encarnadas, tatuadas de maneira irremediável.

\footnotetext{
${ }^{6}$ Quando Bourdieu emprega em sua teoria sociológica a palavra "inconsciente" ele não faz referência à dimensão subjetiva concebida pela psicologia, mas o "inconsciente social", que é fundado no campo social. O sociólogo afirma que o inconsciente nada mais é que o esquecimento da história que a própria história provoca, incorporando as estruturas objetivas que produzem os habitus. Verificar complementação em Bourdieu (2002c).
}

Movimento, Porto Alegre, v. 17, n. 01, p. 281-300, janeiro/março de 2011. 
Mostrando todo o destaque que o autor dá ao corpo e o quanto este pode ser impressionado, modificado e mobilizar-se em condutas a partir das regularidades às quais ele foi exposto, Bourdieu (1980, p.123) afirma que "o que se aprende pelo corpo não é algo que, como um saber, se possa segurar diante de si, mas é algo que se é". Nessa afirmação, o autor se refere a idéia de que o saber aprendido pelo corpo, entendendo este saber como um esquema de sistemas de investimento social que o corpo incorpora, não é palpável. O corpo não representa um papel, não interpreta um personagem e sim se identifica com este formato determinado socialmente, constituindo a partir deste formato a imagem de si, como a imagem que o conforma enquanto indivíduo e por isso mostra o "que ele é".

Reconhecida como sua maneira de ser, o agente não consegue perceber que grande parte do investimento no corpo que visa sua construção socializada é responsável por determinar sua posição de ocupação no espaço social.

Aponta-se, assim, a relevância de identificar os processos de construção do corpo social e analisar as consequências da formatação do corpo e da construção do indivíduo com uma self-image (imagem de si) específica e a contribuição deste indivíduo para sua própria reprodução social. Para Montagner ${ }^{7}$ (2006) o agente possui um capital físico ou corporal, correspondente a uma disposição e uma trajetória individual, mas também possui uma dimensão coletivizada, de grupo, ainda que não se conheçam os mecanismos dessa capacidade de memorização física ${ }^{8}$. ${ }^{7}$ Miguel Ângelo Montagner, foi um dos estudiosos que se dedicou a rever o corpo na teoria
sociológica de Bourdieu realizando um mapeamento do tema da saúde e da medicina nas obras
do autor. Em seus textos, Montagner aponta as aparições do tema na obra de Bourdieu e de
seus colaboradores da Revista Actes de la Recherche en Sciences Sociales. Este autor aponta
algumas linhas de análise atuais e ressalta a importância do corpo na obra de Bourdieu. Constam
nesse trabalho de mapeamento algumas bibliografias básicas ainda pouco conhecidas no Brasil.
Verificar igualmente MONTAGNER, M. Â. Pierre Bourdieu e a saúde: uma sociologia em Actes
de la Recherche en Sciences Sociales. Cad. Saúde Pública, v. 24, n. 7 , p. 1588-1598, 2008.
${ }^{8}$ Pode-se tentar compreender tais mecanismos de memorização física com a leitura de Bourdieu
(2002e, p. 185) quando este descreve um extrato de sua pesquisa empírica que trata da apren-
dizagem da criança cabila, esclarecendo como a criança incorpora as estruturas. Explica que
"enquanto o trabalho pedagógico não é claramente instituído como prática específica e autônoma
e enquanto é todo um grupo e todo um ambiente simbolicamente estruturado que exerce, sem
agentes especializados nem momentos especificados, uma ação pedagógica anônima e difusa,
o essencial do modus operandi que define o domínio prático transmite-se na prática, no estado
prático, sem ascender ao nível do discurso. Não se imitam 'modelos', mas ações dos outros. A

Wovimento, Porto Alegre, v. 17, n. 01, p. 281-300, janeiro/março de 2011. 
Bourdieu (2002b) utiliza a noção de capital corporal, afirmando que as propriedades corporais podem funcionar como capital para a obtenção de lucros sociais, para conceder à representação dominante do corpo um reconhecimento incondicional. Para esse sociólogo, além das propriedades corporais, o capital corporal, também abrangeria a habilidade corporal para a prática de esportes. A aprendizagem de uma habilidade específica seria mais rentável na medida em que se daria de forma precoce. A tradição familiar, a postura, as técnicas de sociabilidades e a aprendizagem precoce de uma habilidade motora, podem interditar alguns esportes e práticas corporais às classes populares. Pode-se afirmar com Bourdieu (2002b) que um esporte tem tantas chances de ser adotado pelos membros de uma classe social quanto mais ele não contradiga a relação do corpo naquilo que há de mais profundo e de mais profundamente inconsciente, ou seja, o esquema corporal, como depositário do corpo próprio.

Destacando a importância do que é apreendido pelo corpo e que se encontra velado à compreensão do agente, Bourdieu (1998a, p.3) afirma que "as injunções são particularmente poderosas porque elas se dirigem primeiramente ao corpo e não passam necessariamente pela linguagem e pela consciência".

A submissão às determinações das disposições se origina na própria incorporação destas disposições. Esta submissão se aloja profundamente no corpo socializado, sendo a expressão do que, na teoria de Bourdieu, se chama a somatização ${ }^{9}$ das relações sociais de dominação. Para o autor, a somatização progressiva das relações

hexis corporal fala imediatamente à motricidade, enquanto esquema postural que é ao mesmo tempo singular e sistemático, porque solidário de todo um sistema de técnicas do corpo e de utensílios e carregados de uma multiplicidade de significações e de valores sociais; e as crianças são particularmente atentas, em todas as sociedades, a esses gestos ou a essas posturas em que se exprime aos seus olhos tudo o que faz o adulto completo, uma atitude, uma posição da cabeça, expressões do rosto, maneiras de se estar sentado, de manejar os instrumentos...". Desta maneira a sociedade inculca as disposições que constroem o corpo social das crianças. Primeiramente são aprendidas com uma observação silenciosa, e depois pelo reforço de tais disposições no processo de socialização.

${ }^{9} \mathrm{Na}$ origem, a acepção da palavra "somatização", está relacionada com "a transformação de conflitos psíquicos em afecções de órgãos ou em problemas psicossomáticos" (HOUAISS, 2001, p.2605), mas aqui traduzida do francês "somatisation" e respeitando o sentido dado por Bourdieu citado por Hong (1999) e, em A Dominação Masculina (2002e) e Actes de la Recherche en Sciences Sociales, $n^{\circ}$ 84, setembro 1990, a palavra "somatização" é empregada no sentido das transformações corporais que acontecem devido à incorporação da ordem social. A ordem social modifica corporalmente o indivíduo produzindo efeitos somáticos, ou seja, efeitos físicos.

Movimento, Porto Alegre, v. 17, n. 01, p. 281-300, janeiro/março de 2011. 
fundamentais que são constitutivas da ordem social inscreve-se na hexis corporal $^{10}$, ou seja, nas posturas, disposições e relações do corpo, interiorizadas pelo indivíduo, induzindo sua maneira de agir, sentir e pensar.

A partir desse exposto, pode-se compreender que o corpo e as técnicas corporais também ocupam a centralidade das argumentações de Bourdieu para explicar as relações de poder e dominação, bem como as referências que o autor faz da noção de violência simbólica. Para Bourdieu (1982) os efeitos da dominação se exercem por intermédio de uma relação de adesão corporal. $\mathrm{O}$ vocabulário da dominação está repleto de metáforas corporais, sendo que a submissão está inscrita nas posturas, na maneira como se curva o corpo e nos automatismos do cérebro. $\mathrm{O}$ autor afirma que os discursos feitos pelos agentes sociais, como formas de comunicação, não conseguem expressar tão bem a dominação e a submissão quanto à "ginástica" da dominação inscrita em seu corpo em que a ordem social se inscreve de forma duradoura.

Os investimentos no corpo e em suas posturas têm destaque no processo de dominação, como princípio de atuação do poder. A concretude desse investimento pode ser verificado, por exemplo, nas instituições de ensino, onde se atesta a associação de duas formas de comunicação e inculcação, a saber, os discursos e a modulagem de um corpo social encarnado em um corpo biológico, servindo de portavoz das crenças socialmente determinadas e aceitas. É o que evoca a noção de "esprit de corps" (espírito de corpo), fórmula que, segundo Bourdieu (1982), é sociologicamente fascinante e aterrorizante.

\footnotetext{
${ }^{10} \mathrm{Em}$ sua teoria sociológica, Bourdieu entende que a hexis é o componente do habitus que traduz as posturas, as disposições do corpo interiorizadas. Em textos posteriores, o sociólogo passa a referir-se às disposições em seus variados aspectos somente como habitus e não mais destacando hexis, ethos ou eidos, para evitar que se pudesse pensar de modo compartimentalizado, reforçando assim a noção de um sistema de disposições que tudo abrange. Para complementar esta noção podemos consultar Champagne (2008) que explica que o corpo está no mundo social, mas o mundo social está no corpo sob forma de postura corporal (hexis), de esquemas de pensamento (eidos) e de apreciação (ethos). Entretanto, no artigo que aqui se apresenta, serão abordadas as duas noções uma vez que a intenção desse texto é tratar das reflexões sobre o corpo que empreendeu Bourdieu ao longo de sua produção científica, alguns, anteriores à sua decisão de referir-se ao habitus pressupondo que engloba todos os três componentes.

Wovimento, Porto Alegre, v. 17, n. 01, p. 281-300, janeiro/março de 2011.
} 
Bourdieu (2002b, p. 553) explica a aceitação da dominação e o papel decisivo do corpo, afirmando que a socialização, ou seja, o que forma o corpo social, constitui o corpo como um "operador analógico", instaurando todo tipo de equivalências práticas. Segundo o autor, isto ocorre pela integração da linguagem corporal, que contribui de forma poderosa para modelar o habitus com a dominação simbólica e a submissão social. Esta integração revela a adaptação a uma posição dominada, implicando uma forma de aceitação da dominação.

O efeito da dominação simbólica sobre o corpo é tratado por Bourdieu (2002e, p. 50) como uma "força mágica", ou seja, uma força simbólica como "forma de poder que se exerce sobre os corpos, diretamente, e como que por magia, sem qualquer coação física; mas essa magia só atua com o apoio de predisposições colocadas, como molas propulsoras, na zona mais profunda dos corpos". O autor explica ainda que esta força simbólica age como um macaco mecânico, ou seja, com um pequeno gasto de energia desencadeia reações de um trabalho prévio de incorporação que operou transformações duradouras nos corpos, produzindo disposições permanentes. É sob forma de esquemas de percepções e de disposições que se inscreve um sistema de estruturas nos corpos dos dominados, tornando-os sensíveis a certas manifestações simbólicas do poder e aptos a entrar no jogo social. A ordem social determina a ordem do corpo, tornando-o ao mesmo tempo lugar de investimento e princípio de sua eficácia.

\section{TEXTOS E CONTEXTOS: ALGUMAS REFERÊNCIAS SOBRE O CORPO NA OBRA DE PIERRE BOURDIEU}

A partir de uma genealogia deste tema nos escritos de Bourdieu, pode-se perceber que as reflexões sobre o corpo já estavam presentes nos anos 1960 (portanto, no início de sua produção), nas observações realizadas na Argélia ${ }^{11}$. Segundo Mounier (2001) foi observando que

\footnotetext{
${ }^{11}$ Em seu "Esboço de auto-análise", Bourdieu (2005) relata o quanto sua experiência na Argélia e o desafio intelectual e pessoal que representou sua estada em um país em plena guerra de independência, foram fundamentais para sua percepção do campo sociológico. Isso se deu

Movimento, Porto Alegre, v. 17, n. 01, p. 281-300, janeiro/março de 2011.
} 
a inversão simbólica entre o interior e o exterior da casa cabila era também uma inversão geométrica, e assim corporal, que Bourdieu começou a introduzir em suas análises uma Sociologia do corpo. Para este comentador é notadamente, o caso de suas observações sobre o habitus masculino e feminino na sociedade cabila que se fundamenta em grande parte sobre uma oposição de atitudes corporais.

Paralelamente às pesquisas na Argélia, o autor também investigava o celibato dos filhos mais velhos no Béarn ${ }^{12}$. Em um de seus textos em que apresenta a descrição do corpo camponês é que aparece pela primeira vez em sua obra o termo habitus ${ }^{13}$. Segundo Sapiro (2004) esta primeira menção do termo habitus na obra de Bourdieu acontece associada à hexis, a partir da referência de Marcel Mauss e sua análise das técnicas do corpo. Explica Sapiro (2004) que, segundo Mauss, o termo habitus, emprestado da tradição aristotélica-tomista, e empregado de maneira ocasional por Hegel, Husserl, Weber e Durkheim, traduzia melhor que hábito, a hexis, o adquirido corporalmente. Para Mauss, seria pela educação e especialmente pelo adestramento do corpo que são interiorizadas, incorporadas, não somente representações sociais, mas, igualmente, as regras de conduta e as práticas.

\footnotetext{
não só pela ruptura com sua experiência escolar (a passagem da Filosofia para a Etnologia e desta para a Sociologia), mas pela visão crítica da Sociologia e dos sociólogos. Passando a interessar-se pela sociedade argelina, empreende trabalhos de campo e suas pesquisas sistemáticas culminaram em várias obras. Relembra a necessidade de uma reflexividade permanente e prática, indispensável nas condições de urgência e risco que se encontrava em que tudo parecia ser questionado o tempo todo e que originou a vigilância crítica que aplicou em seus trabalhos posteriores.

12 Tais pesquisas deram origem a três artigos sucessivos compilados no livro intitulado Le Bal des Célibataires. Crise de la societé paysanne en Béarn, Paris: Seuil, 2002, ainda sem tradução para o português. Alguns extratos do livro podem ser colhidos na Revista de Sociologia e Política, Curitiba, 26, jun., 2006, pp. 83-92. Vale lembrar que o Béarn é a região de origem de Pierre Bourdieu e que o sociólogo, nessas investigações, toma como objeto de análise um mundo que the é familiar realizando um trabalho de reflexividade, entendida com objetivação científica do indivíduo da objetivação, recurso que ele definiria como fundamental no ofício de sociólogo. Para mais detalhes consultar BOURDIEU, 2005.

${ }^{13}$ Para Sapiro (2004), após a sua utilização da noção de habitus no texto acima citado a partir de Mauss, como técnicas do corpo, o conceito foi sistematizo por Bourdieu com a leitura de Panofsky para passar a figurar como um conceito chave de sua teoria sociológica. Em Architecture gothique et pensée scolastique (1967) que Bourdieu traduziu para a coleção Le Sens Commun, escreveu um posfácio centrado na noção de habitus que Panofsky emprega para designar as categorias de percepção comuns à cultura escolástica e à arte gótica, formando assim um modus operandi, ou seja, um princípio unificador de práticas.
}

Movimento, Porto Alegre, v. 17, n. 01, p. 281-300, janeiro/março de 2011. 
Ainda em Sapiro (2004) lê-se que a partir daí, em sua teoria sociológica, Bourdieu vai afirmar que o corpo socializado "pensa"; que é um corpo "habituado", mas afastando-se de explicações mecanicistas, notadamente da explicação behaviorista que procura os fundamentos fisiológicos do comportamento. Para Bourdieu o corpo é também lugar da prática, da invenção e da improvisação de condutas mais ou menos ajustadas às situações (sua faculdade de improvisação é limitada pelas condições de sua socialização).

No texto "O camponês e seu corpo", Bourdieu (2006) vai explorar a relação entre a tendência do camponês do sexo masculino permanecer solteiro e o local em que vive, bem como as características econômicas, sociais e psicológicas ligadas a este local de residência. Tal fato se daria pela inabilidade do camponês que se mostra mal adaptado e desconcertado nas ocasiões institucionalizadas de encontro entre os sexos como, por exemplo, nos bailes.

Realizando a observação de determinado evento social neste formato, em que o modelo urbano irrompe a vida camponesa com suas representações culturais, Bourdieu (2006) faz a descrição e interpretação das técnicas corporais - que segundo o autor seriam verdadeiros sistemas solidários a todo um contexto cultural - e dos depoimentos dos solteiros, desenhando a condição campesina a partir do corpo.

Com fim de exemplificação, Bourdieu (2006, p. 86) utiliza a dança. Afirma que as danças de antigamente eram solidárias à civilização camponesa. Já as modernas seriam solidárias à civilização urbana, exigindo a adoção de novas atitudes corporais, demandando "mudanças de 'natureza', dado que o habitus corporal consiste naquilo que se vive como mais natural, aquilo sobre o que a ação consciente não tem controle".

Assim para o autor, não somente a aparência e as formas de ser e expressar-se, ou seja, a hexis corporal, funcionariam como um signum social, mas também os movimentos do corpo em diversas situações. O camponês tende a introjetar em seu corpo a imagem que os moradores da cidade fazem dele, mesmo que se trate de um estereótipo. Segundo Bourdieu (2006, p. 87), o camponês

Movimento, Porto Alegre, v. 17, n. 01, p. 281-300, janeiro/março de 2011. 


\begin{abstract}
$[\ldots]$ passa a perceber seu corpo como corpo cunhado pela impressão social, como corpo empaysanit, rude, carregando o traço das atitudes e atividades associadas à vida camponesa. Em conseqüência, fica embaraçado em relação a seu corpo e em seu corpo. É por apreender seu corpo como corpo rude que toma consciência de ser camponês rústico. Não é exagero presumir que a tomada de consciência de seu corpo é, para o camponês, a ocasião privilegiada da tomada de consciência da condição camponesa.
\end{abstract}

Para Bourdieu (2006) a partir da noção de seu corpo, o camponês deixa de se sociabilizar, adotando uma atitude introvertida que o impede de dançar, de ter atitudes simples e naturais na presença das moças. A consciência do camponês do que lhe resta desta condição corporal, econômica e social, influi na tendência para o casamento.

Entre outros textos ${ }^{14}$, podem-se citar as reflexões sobre o corpo, como as encontradas em "Esboço para uma teoria da prática, precedido de três estudos de etnologia cabila", escrito originalmente em 1972. Nesse livro, encontram-se apontamentos sobre as "estruturas, habitus e práticas"; a "incorporação das estruturas" e o "corpo geometra", respectivos nomes dos capítulos três, quatro e cinco. Na referida obra, Bourdieu vai desenhar de forma mais clara o conhecimento praxiológico por ele desenvolvido, vai lapidar o conceito de habitus e sua teoria da prática, "condição da construção de uma ciência experimental da dialética da interioridade e da exterioridade, isto é da interiorização da exterioridade e da exteriorização da interioridade" ${ }^{15}$.

Em um artigo publicado na Revista Actes de la Recherche en Sciences Sociales de 1977 intitulado "Remarques provisoires sur la perception sociale du corps" (Observações provisórias sobre a percepção social do corpo), Bourdieu afirma que o corpo, como

\footnotetext{
${ }^{14}$ Alerta-se que o objetivo deste artigo não é o de trazer uma exaustiva compilação de todos os textos e obras em que Bourdieu aborda o corpo social, mesmo porque, como se pode perceber pelo aqui argumentado, a partir da conexão deste tema com o conceito de habitus, dever-se-ia listar praticamente toda a relação de trabalhos do autor. Procura-se, portanto, identificar suas primeiras incursões e reflexões sobre o corpo como auxiliar para pensar os processos de socialização nas referências mais diretas sobre o assunto.

15 ORTIZ, 2003, p. 53
}

Movimento, Porto Alegre, v. 17, n. 01, p. 281-300, janeiro/março de 2011. 
uma forma perceptível que causa uma impressão é, de todas as manifestações do indivíduo, a que menos se deixa modificar, apesar de investimentos de ordem variada. O corpo deve ser levado em consideração por significar de forma mais adequada a natureza de uma pessoa, funcionando, portanto, como uma forma de linguagem da identidade social em que "se é falado, mais do que se fala" ${ }^{16}$. No corpo se leria a linguagem da natureza cultivada em que se trai o mais escondido e o mais verdadeiro, já que o menos conscientemente controlado e controlável e que contamina e determina as mensagens percebidas e despercebidas.

O corpo, nas reflexões de Pierre Bourdieu retratadas nesse artigo, é um produto social desde as dimensões de sua conformação visível, que tem a ver com os hábitos de consumo, gostos, ou seja, habitus, derivados de condições sociais, até nas formas de se portar e de se comportar, em que se expressa toda a relação com o mundo social.

Em “A Distinção, crítica social do julgamento”, de 1979, Bourdieu continua a tratar do corpo em paralelo com suas análises dos estilos de vida, ou seja, do conjunto dos gostos (faculdade de perceber os sabores e capacidade de julgar valores estéticos) e das práticas sistemáticas de uma classe ou a fração de determinado extrato social. Conforme já mencionado em outras passagens desse artigo para as quais a obra foi consultada, Bourdieu (2002b, p.171) destaca que as aquisições incorporadas são determinadas socialmente e se inscrevem no corpo na maneira de se portar, de se movimentar e cuidar do corpo. Com relação a este último tópico, o sociólogo destaca a manipulação "entre o ser e o dever-se ser em tudo que concerne à imagem ou a utilização do corpo", que conta com a cumplicidade inconsciente daqueles que contribuem para a produção de um mercado inesgotável de produtos que são oferecidos para impor uma nova hexis corporal, dimensão fundamental do senso de orientação social.

Bourdieu (2002b) afirma que o gosto contribui para fazer o corpo de classe pela cultura tornada natureza, ou seja, incorporada,

${ }^{16}$ BOURDIEU, 1977, p. 51.

Movimento, Porto Alegre, v. 17, n. 01, p. 281-300, janeiro/março de 2011. 
que escolhe e modifica tudo que o corpo ingere, digere e assimila. $\mathrm{O}$ corpo é, portanto, a objetivação mais irrecusável do gosto de classe.

Também em 1979, Pierre Bourdieu escreve o artigo "Os três estados do capital cultural" em que destaca o estado incorporado como uma das três formas de existir do capital cultural e, mais ainda, afirma que este seria seu estado fundamental. Ligado ao corpo e pressupondo sua incorporação, a acumulação desse tipo de capital cultural demandaria um trabalho de inculcação e de assimilação que custaria tempo de investimento do agente social, tal como um "bronzeamento" 17 .

Em 1980, escreve "Le Sens Pratique" em que lapida o conceito de habitus e "Questões de Sociologia" em que aborda em vários dos textos reunidos na obra, a problemática do corpo, das práticas corporais e da mimesis corporal. Em uma passagem bastante significativa para entender a centralidade do corpo em suas teorizações, Bourdieu (2002c) fala da história feita coisa e a história feita corpo. Nesse extrato de texto, afirma que a história está inscrita nas coisas, ou seja, nas instituições (nas máquinas, nos instrumentos, nas teorias científicas, etc.) e também no corpo. Todo seu esforço teria consistido em descobrir a história onde ela se esconde melhor, a saber, nos cérebros e nas dobras do corpo. Para o autor, o inconsciente é história e esta afirmação explicaria as categorias de pensamento e de percepção que são aplicadas espontaneamente no mundo social, bem como se explicaria que quando a história feita corpo entra em acordo perfeito com a história feita coisa, tem-se uma cumplicidade tácita dos dominados com a dominação.

Na sequência do empreendimento científico de Pierre Bourdieu, as reflexões sobre o corpo, seja a partir do habitus, do capital cultural, do capital corporal ou de suas análises sobre os diversos campos que observa, ainda se fazem presentes em outras obras desse sociólogo, tais como Coisas Ditas (1987), Meditações Pascalianas (1997), tratando do conhecimento pelo corpo, de habitus e incorporação e coerção pelo corpo; e a Dominação Masculina (1998), abordando a construção social dos corpos e a incorporação da dominação; por isso

${ }^{17}$ BOURDIEU, 1998b, p. 74.

Movimento, Porto Alegre, v. 17, n. 01, p. 281-300, janeiro/março de 2011. 
algumas passagens desses livros foram utilizadas na argumentação da primeira parte desse artigo.

Resta discutir de que forma podem-se articular as noções de Bourdieu sobre o corpo e empregá-las para refletir sobre os processos de socialização e as lógicas práticas dos agentes sociais nos campos.

\section{EM CONCLUSÃO: A ARTICULAÇÃO DAS REFLEXÕES DE BOURDIEU SOBRE O CORPO E SUA RELEVÂNCIA COMO FERRAMENTA CONCEITUAL.}

A partir do que foi até aqui exposto, pode-se concordar com Détrez (2006) para quem três grandes eixos articulados entre si podem ser percebidos nas reflexões sobre o corpo empreendidas por Pierre Bourdieu, a saber, o corpo como manifestação do habitus, o corpo como lugar do senso prático e o corpo como enjeux (aposta, mecanismo, investimento) de poder e dominação.

Esses eixos poderiam ser tomados como referência para investigações sobre os processos de socialização nos mais diferentes campos, tornando a sistematização das reflexões de Bourdieu sobre o corpo como uma importante ferramenta conceitual para compreensão do agente social e suas lógicas de ação.

Explorando cada um dos eixos conforme as sistematizações de Détrez (2006), pode-se afirmar que o corpo seria o lugar do senso prático, pois a inteligência do corpo funcionaria além da linguagem e da consciência, uma vez que o corpo age mais a partir do reflexo que a partir de atividades reflexivas. Com a aquisição e a interiorização de saberes incorporados, do savoir-faire, adquiridos na e para a prática, como um verdadeiro conhecimento pelo corpo, o agente social consegue estabelecer relações nos campos sociais uma vez que as aplicações e manifestações do corpo são tão diversas quanto são as situações às quais pode vir a ser envolvido no espaço social.

Pode-se perceber nas discussões da primeira parte do artigo que nas teorizações de Bourdieu o habitus é o corpo biológico socializado ou ainda é o social biologicamente individuado pela encarnação em

Movimento, Porto Alegre, v. 17, n. 01, p. 281-300, janeiro/março de 2011. 
um corpo ${ }^{18}$. Assim, contra a primeira evidência que faria do corpo um dado genético, a teoria do habitus faz do corpo o produto de uma construção social. O corpo como manifestação do habitus revela que as escolhas alimentares, esportivas, habilidades motoras, contribuem para modelar os corpos das classes sociais, ou seja, cada técnica do corpo (forma de se portar, de se movimentar), longe de revelar escolhas pessoais, é a marca de uma relação com o corpo naquilo que ele possui de mais profundo e de mais profundamente inconsciente, o esquema corporal, como depositário de toda uma visão do mundo social e de pertencimento a determinado grupo social.

Consequentemente, como manifestação de pertencimento social, o corpo seria o local de aplicação e de reprodução das formas de dominação (social, física e simbólica) e consequentemente um lócus de aposta, de mecanismo, de investimento, de enjeux privilegiado para o exercício de violência simbólica.

Mas como a sistematização das reflexões de Bourdieu sobre o corpo nesses três eixos, pode-se tornar uma ferramenta conceitual importante para investigar, com o quadro teórico de análise do sociólogo, os processos de socialização em campos variados, esforçando-se para desvelar e compreender o agente social e suas lógicas de ação?

Primeiramente deve-se levar em consideração a obra aberta legada por Pierre Bourdieu, o movimento de seu pensamento, suas disposições e instrumentais científicos e sua recusa na rotinização da prática científica. Deve-se observar, igualmente, a não fragmentação da apropriação de seu arcabouço teórico-metodológico e a não mecanização da aplicação dos conceitos por ele desenvolvidos, encontrando assim novas formas de se realizar pesquisas.

Com essa predisposição, podemos refletir com Montagner (2006), para quem apesar da importância da Sociologia do corpo na teoria da prática, resta ainda inexplorada uma vasta gama de fenômenos simbólicos a serem investigados, sendo que o conceito de habitus poderia ser eficiente para o entendimento sobre a mediação

${ }^{18}$ BOURDIEU, 2001, p. 191.

Movimento, Porto Alegre, v. 17, n. 01, p. 281-300, janeiro/março de 2011. 
entre o agente social e as categorias coletivas, a partir de explicações que abrangeriam a premissa corporal.

Buscando um exemplo que traga a concretude e possibilidade real de tal empreitada pode-se citar Wacquant $(2003,2008)$ que apresenta uma radicalização empírica e metodológica da teoria do habitus de Bourdieu, abrindo a caixa preta do campo social que examinou (uma modalidade do campo esportivo), mostrando a produção e a junção das categorias cognitivas e das destrezas corporais. A radicalização está no processo de imersão que o sociólogo empreendeu no campo, realizando uma "Sociologia Carnal", que foi capaz de restituir o sabor e a dor da ação social, que para Wacquant (2003) seria uma maneira de levar a sério o fato de que o agente social é um ser com disposições incorporadas e que o sociólogo também deveria, na medida do possível, compreender com o corpo.

Mas o processo investigativo que envolve a teoria da ação pode se desenrolar de forma reflexiva a partir de uma observação participante menos que uma "participação observante" à moda de Wacquant (2008, p. 175), contanto que o pesquisador do espaço social preocupe-se em compreender como o agente social é produzido, que capacidades de agir, de sentir e de pensar o torna adequado para o universo social ao qual pertence (lembrando que a aprendizagem de tais capacidades se faz também pelo corpo) que procure detectar que disputas estão se desenrolando nesse universo, para o aumento ou manutenção de que posições no campo e de que capitais, pressupondo um olhar para os lucros sociais incorporados.

Por fim, a utilização da ferramenta conceitual CORPO nas análises sociológicas que se desenvolvam a partir do referencial de Pierre Bourdieu, deve respeitar a visão desse sociólogo sobre a investigação do espaço social e seu objetivo ao pesquisá-lo, a saber, desvelar e analisar as relações de força e os mecanismos de dominação simbólica, bem como explicar a realidade social e tentar compreender as condições do mundo contemporâneo.

Movimento, Porto Alegre, v. 17, n. 01, p. 281-300, janeiro/março de 2011. 
Habitus and social body: reflections about the body in Pierre Bourdieu's sociological theory

Abstract: This paper has as a goal to discuss how the reflections about the body are present in Pierre Bourdieu's sociological theory, articulating the concept of habitus and the social construction of the body. This link can be found in Bourdieu's works in which he analyzes the incorporated dispositions, the body schema, the movements, the techniques and the uses of the body. It was also observed that Bourdieu reflects about the theme linking it in three axes, namely the body as a place of practical sense, the body as a manifestation of habitus and body as an investment of power and domination. This understanding helps in the use of the theoretical framework of analysis developed by the sociologist to investigate the socialization process, becoming an important conceptual tool.

Keywords: Human body. Sociology. Pierre Bourdieu. Social values.

Habitus y cuerpo social: reflexiones sobre el cuerpo en la teoría sociológica de Pierre Bourdieu

Resumen: Este artículo se propone discutir cómo las reflexiones sobre el cuerpo están presentes en la teoría sociológica de Pierre Bourdieu, articulando el concepto de habitus y la construcción social del cuerpo. Este enlace se puede encontrar en varias obras de Bourdieu en que examina las disposiciones incorporadas, el esquema corporal, los movimientos, técnicas y usos del cuerpo. Se observó también que Bourdieu reflexiona sobre los vínculos de este tema en tres ejes, a saber, el cuerpo como lugar del sentido común, como una manifestación del habitus y el cuerpo como una inversión de poder y dominación. Este entendimiento ayuda en la utilización del marco teórico de análisis desarrollado por el sociólogo para investigar el proceso de socialización, convirtiéndose en una herramienta conceptual importante.

Palabras-clave: Cuerpo Humano. Sociologia. Pierre Bourdieu. Valores sociales.

Wovimento, Porto Alegre, v. 17, n. 01, p. 281-300, janeiro/março de 2011. 


\section{REFERÊNCIAS}

BOURDIEU, P. Ce que parlet veut dire. Entrevista com Didier Éribon. Libération, Paris, 19 out. 1982.

. Le corset invisible. Entrevista com Catherine Portevin. Télérama (3), Paris, n. 2534,5 ago. 1998 a

La distinction, critique sociale du jugement. Paris: Minuit, 2002b.

A dominação masculina. Rio de Janeiro: Bertrand Brasil, 2002e.

Esboço de auto-análise. São Paulo: Companhia das Letras, 2005.

Esboço para uma teoria da prática, precedido de três estudos de etnologia cabila. Oeiras: Celta, 2002d.

. A gênese dos conceitos de habitus e de campo. In BOURDIEU, P. O poder simbólico. Rio de Janeiro: Bertrand Brasil, 2002a.

. Le sens pratique. Paris: Minuit, 1980.

Meditações pascalianas. Rio de Janeiro: Bertrand Brasil, 2001.

O camponês e seu corpo. Revista de Sociologia e Política, Curitiba, junho, n. 26, p. 83-92, 2006.

. Os três estados do capital cultural. In: NOGUEIRA, M. A.; CATANI, A. Escritos de educação. Petrópolis: Vozes, 1998b. p. 71-79.

Questions de sociologie. Paris: Minuit, 2002c.

Remarques provisoires sur la perception sociale du corps, Actes de la

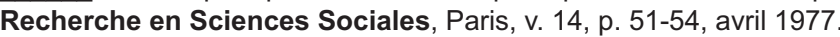

CHAMPAGNE, P. Pierre Bourdieu. Toulouse: Milan, 2008.

DÉTREZ, C. Corps in CAZIER, J-P (Org.). Abécédaire de Pierre Bourdieu. Paris: Vrin, 2006.

HANKS, W. F. Língua como prática social: das relações entre língua, cultura e sociedade a partir de Bourdieu e Bakhtin. São Paulo: Cortez, 2008.

HONG, S. M. Habitus, corps, domination: sur certains presupposes philosophiques de la sociologia de Pierre Bourdieu. Paris: L' Harmattan, 1999.

HOUAISS, A. Dicionário Houaiss de língua portuguesa. Rio de Janeiro: Objetiva, 2001.

MONTAGNER, M. Â. Pierre Bourdieu e a saúde: uma sociologia em Actes de la Recherche en Sciences Sociales. Cadernos Saúde Pública, v. 24, n. 7, p. 1588-

Movimento, Porto Alegre, v. 17, n. 01, p. 281-300, janeiro/março de 2011. 
1598,2008

Pierre Bourdieu, o corpo e a saúde: algumas possibilidades teóricas. Ciência saúde coletiva, Rio de Janeiro, v. 11, n. 2, p. 515-526, jun. 2006,

MOUNIER, P. Pierre Bourdieu: une introduction. Paris: Pocket, 2001.

ORTIZ, R. A Sociología de Pierre Bourdieu. São Paulo: Olho d’Água, 2003.

SAPIRO, G. Une liberté contrainte. La formation de la théorie de l'habitus. In. PINTO, L.; SAPIRO, G.; CHAMPAGNE, P. Pierre Bourdieu: sociologue. Paris: Fayard, 2004.

WACQUANT, L. O corpo, o gueto e o estado penal. In: DURÃO, S. Entrevista com Loïc Wacquant. Etnográfica, Lisboa, v. 2, n. 2, p. 455-486, nov. 2008,

Introduction. In: BOURDIEU, P. Réponses: pour une anthropologie réflexive. Paris: Seuil, 1992.

Seguindo Bourdieu no campo. Revista de Sociologia e Política, Curitiba, n. 26, p. 13-29, jun. 2006.

. Une expérience de Sociologie Charnelle. Entretien avec Loïc Wacquant. Solidarités, Genebra, n. 29, p. 18-20, jun. 2003.

Movimento, Porto Alegre, v. 17, n. 01, p. 281-300, janeiro/março de 2011. 